\title{
A clinical study to predict the outcome of patients with hollow viscus perforation in a tertiary care hospital using manheim peritonitis index
}

\author{
Ramaswamy Naik $\mathbf{M}^{1}$, Sailaja $K^{2}$ \\ ${ }^{1}$ Dr. Ramaswamy Naik M., Professor and Head, ${ }^{2}$ Dr. Sailaja K., Associate Professor, Department of General Surgery, \\ Government Medical College and Government General Hospital, Anantapuramu, Andhra Pradesh, India.
}

Corresponding Author: Dr. K. Sailaja, Associate Professor of General Surgery, Government Medical College and Hospital, Anantapuramu. E-mail: sailaja7074@gmail.com

\begin{abstract}
Introduction: Since a longtime multiple effort are been put forwarded to design an effective scoring system as to predict the outcome as to mortality and morbidity of patients admitting to hospitals with hollow viscus perforations. Of number of proposed systems Mannheim Peritonitis index is quite simple and effective scoring system proposed to predict the outcome of the patients admitted to hospital with hollow viscus perforations. Objective: To assess the validity of Mannheim Peritonitis Index (MPI) for predicting the surgical outcome, mortality and morbidity of cases presenting with Hollow viscus perforation. Method: Current prospective study was one over a period of three years form 2014-2017 at Department of Surgery, Government Medical College, Anantapuramu and included 100 cases between 17-46 years of age. Results: The results of the current study indicated that duodenal perforations are common amongst the hollow viscus perforations, clear exudates were common among peritonitis cases. about 50\% of cases presented with postoperative complications. Subjects fitting into MPI scores between 22-29 presented with surgical site infections. higher MPI scores are associated to higher ICU stays. Higher score are observed in cases with feculent and purulent exudates and in turn to relatively more number of complications. Conclusion: The Mannheim Peritonitis index provide a novel and excellent platform as to predict the surgical outcome, mortality and morbidity in cases of hallow viscera perforations with peritonitis with all associated issues related to the conditions.
\end{abstract}

Keywords: Hollow viscus perforation, Mannheim Peritonitis Index (MPI) scoring system, Surgical outcome

\section{Introduction}

It has been always a herculean task to predict and counsel as to the outcome of various surgeries performed in a health set up. Numerous scoring systems have been proposed and are used to predict the outcome of various surgeries for certain benign conditions like acute cholecystitis, acute pancreatitis etc. It is expected that the scoring system should be easily applicable, accountable and to be reproducible by other people or teams who are working on similar conditions.

The scoring systems should help the medical fraternity and supporting staff to explain to the patient and their attendants regarding the expected surgical outcome of the patient. It should also help to have improved monitoring of the patient and also assess the healthcare facilities available in that particular institute. Though not that common, the incidence of hollow viscus

Manuscript Received: $27^{\text {th }}$ April 2018

Reviewed: $7^{\text {th }}$ May 2018

Author Corrected: $14^{\text {th }}$ May 2018

Accepted for Publication: $17^{\text {th }}$ May 2018 perforations are presenting at Emergency and surgery departments frequently. The mortality and morbidity associated with hollow viscus perforation is also high especially due to their diagnostic difficulty and delayed complications. There are many scoring systems available to predict the outcome of the surgery in cases of hallow viscera perforations.

To name a few we have Mannheim Peritonitis Index, Reiss Index, Fitness score. Surgical Risk scale, POSSUM and P-Possum scores etc [1-6]. Of these available scoring systems, Mannheim Peritonitis Index (MPI) is relatively superior as it takes a balanced view of clinical features and operative findings.

Mannheim Peritonitis Index (MPI) was developed by Wacha and Linder in 1983[7] based on the retrospective data from 1253 subjects with peritonitis and include twenty probable inherent risk factors were considered. Of these twenty factors only eight factors proved to 


\section{Original Research Article}

have prognostic significance and were entered into the MPI and are classified according to predictive powers [8]. In the aforementioned background the current study is undertaken to evaluate the outcome of frequently performed surgery for hollow viscus perforation, to select a scoring system the suits better for our institution to be taken as a standard protocol and to assess the validity of Mannheim Peritonitis Index for predicting the surgical outcome, mortality and morbidity of cases presenting with Hollow viscus perforation.

\section{Materials and Methods}

The current prospective study is undertaken at Department of General Surgery, Government Medical College and General Hospital, Anantapuramu from January 2014 to January 2017 after obtaining clearance from Institutional Ethical committee. The study encompassed a total of 100 cases who are in the age group of 14 to 76 years and has a clinical, radiological indication of gastrointestinal perforations. Consent was obtained from patients or from their attendants after explaining study protocol.

Inclusion criteria- Patients with clinical suspicion and investigatory support for the diagnosis of peritonitis due to hollow viscous perforation who are later confirmed by intra operative findings. Various etiologies causing such features include Acid peptic disease, Typhoid, Gangrenous cholecystitis, Appendicitis, Malignancy.

Exclusion Criteria- Patients with history of abdominal trauma, viral screening positive and females who are pregnant are excluded from the study. Patients presenting with peritonitis after basic investigations and radiological assessment undertaken for emergency laparotomy after intraoperative confirmation of the site of the perforation.

The Mannheim Peritonitis Index: The Mannheim Peritonitis Index (MPI) developed by Wacha H and Linder MM [7] in 1983 is used in the current study as to assess mortality and morbidity of cases. The scoring criteria in the MPI are depicted in Table No.1 below.

Table-1: Mannheim Peritonitis Index.

\begin{tabular}{|c|l|c|}
\hline S. No & Criteria & Score \\
\hline 1 & Age ( $>50$ years) & 5 \\
\hline 2 & Female sex & 5 \\
\hline 3 & Organ failure & 7 \\
\hline 4 & Malignancy & 4 \\
\hline 5 & Pre-operative duration of peritonitis & 6 \\
\hline 6 & Diffuse generalized peritonitis & 6 \\
\hline 7 & Nature of peritoneal fluid & 6 \\
& $\bullet \quad$ clear & 12 \\
\hline
\end{tabular}

Organ failure criteria: For the study purpose mortality is taken as death of subject occurring during the study period and morbidity is defined as a prolonged hospital stay is warranted for more than 2 weeks or a repeat laparotomy is needed. As for as Organ failure criteria is concerned, the considerations are Creatinine level of more than 177 micro mol per liter, Urea levels of greater than $167 \mathrm{mmol}$ per liter, Oliguria with less than $20 \mathrm{ml}$ of urine output per hour, $\mathrm{PaO} 2$ of less than 50 , $\mathrm{mm}$ of hg, $\mathrm{Pa} \mathrm{CO} 2$ of more than $50 \mathrm{~mm}$ of $\mathrm{Hg}$, Shock: systolic blood pressure less than $90 \mathrm{~mm}$ of $\mathrm{Hg}$ and $\mathrm{Mean}$ Arterial Pressure of less than $60 \mathrm{~mm}$ of $\mathrm{Hg}$.

Method: Once the subjects are included in the study, using history, clinical examination, and lab values risk factors found in MPI were classified according to values indicated and individual variable scores were added to establish MPI score. The cases were first grouped into three, as described by Billing: those below 21 points, between 21-29 points, and those above 29 points [9]. In addition to personal data such as name, age, sex, etc., the following information was 
Original Research Article

registered: file number; dates of admission and discharge from the hospital; days hospitalized; date of surgery and information related to illness (surgical findings, medical treatment and evolution of illness). Patient evolution was followed, occurrence of complications and discharge due to improvement or death. Time elapsed from initial diagnosis to moment of event (death or discharge from hospital) was determined. Out-patient follow-up was continued for 30 days to establish perioperative morbidity and mortality. The minimum possible score was zero, if no adverse factor were present, and maximum was 47 if presence of all were confirmed. Analysis was done with each variable in the scoring system as an independent predictor of morbidity or mortality and the scoring system as a whole. The data obtained from the study is recorded in a pretested proforma and was analyzed using SPSS software version 16.3. Each variable in the index and clinical data were analyzed with chi square analysis. p-value $<0.05$ was taken as significant.

\section{Observations and Discussion}

Site of perforation: It is observed from table No.2 that of a total number of 100 cases included in the study, Duodenum was the commonest site of perforation as seen in $58 \%$ of the cases followed by Ileal perforation in $18 \%$ of cases, Appendicular perforation in $14 \%$ of cases and gastric perforation in $10 \%$ of the cases. Similar findings were noticed in a study conducted by Smith etal [10] and Watts DD etal[11].

Table-2: Distribution of cases as to site of perforation.

\begin{tabular}{|c|c|c|}
\hline Site of perforation & Frequency(n) & Percentage (\%) \\
\hline Gastric & 10 & 10 \\
\hline Duodenal & 58 & 18 \\
\hline Ileal & 18 & 14 \\
\hline Appendicular & 14 & 100 \\
\hline Total & 100 & 58 \\
\hline
\end{tabular}

Type of exudate: It is evident from Table No.3 that Clear exudate was observed in majority of the cases included in the study amounting to $60 \%$ of total cases followed by purulent and feculent exudates in $26 \%$ and $14 \%$ of cases respectively. Results are comparable with studies conducted by Ramachandra etal[12]

Table-3: Distribution of cases as to type of exudate

\begin{tabular}{|c|c|c|}
\hline Exudate & Frequency(n) & Percentage (\%) \\
\hline Clear & 60 & 60 \\
\hline Purulent & 26 & 26 \\
\hline Feculent & 14 & 14 \\
\hline Total & 100 & 100 \\
\hline
\end{tabular}

Post-operative complications: As assessed from Table No-4 and Graph No.1 below 58\% of study population did not had any postoperative complications while $20 \%$ of cases had two or more complications and remaining cases presented with single complication. Relatable findings are presented in the work done by Pacelli F etal [13] and Lohsiriwat V et al [14].

Table-4: distribution as to postoperative complications.

\begin{tabular}{|c|c|c|}
\hline Postoperative complication & Frequency(n) & Percentage (\%) \\
\hline Present & 42 & 42 \\
\hline Absent & 58 & 58 \\
\hline Total & 100 & 100 \\
\hline
\end{tabular}


Original Research Article

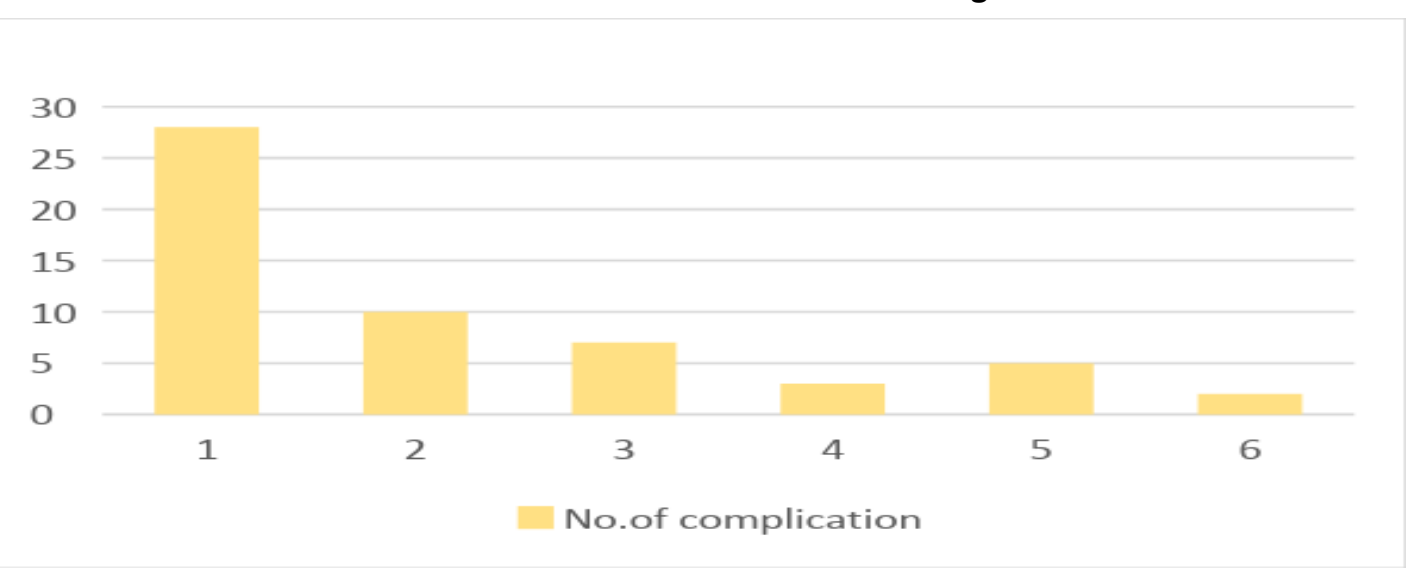

Graph-1: Postoperative complications

Distribution of cases as to MPI Scoring: It can be deduced from the table no-5 that most of the cases amounting to about $64 \%$ fall under a MPI score of $<22$ (low risk group). About $22 \%$ of cases fit into MPI scoring between $22-29$ and $14 \%$ cases fit into MPI scoring of $>14 \%$ (high risk group). Patients with organ failure at admission, prolonged illness before surgery, diffuse peritonitis, feculent exudates were tending to have higher scores and hence fall into high risk group than their counter parts. Identical results were observed in studies conducted elsewhere [15-18].

Table-4: Distribution of cases as per MPI scoring.

\begin{tabular}{|c|c|c|}
\hline MPI Scores & Frequency(n) & Percentage (\%) \\
\hline$<22$ & 64 & 64 \\
\hline $22-29$ & 22 & 22 \\
\hline$>29$ & 14 & 14 \\
\hline Total & 100 & 100 \\
\hline
\end{tabular}

Distribution of cases as per Mannheim peritonitis score in relation to Surgical site infections (SSI): It can be observed form table No.5 that up to $60 \%$ of the patients developed wound related complications in the postoperative period which was about $40 \%$ in patients with score $22-29$ and about $12 \%$ in patients with scores $<22(\mathrm{p}-<0.005)$. The postoperative complications were significantly higher in the development of multi organ failure. There was only death the study done. Analysis didn't reach significant figures. Similar postulations were observed in studies conducted by Blondo etal [18], Lohsiriwat etal [6] and Seiler etal[19]

Table-5: distribution of cases as per MPI in relation to SSI.

\begin{tabular}{|c|c|c|c|c|}
\hline SSI & Scores $<22$ & Scores 22-29 & Score $>29$ & Total \\
\hline No & 56 & 12 & 06 & 74 \\
\hline & $75.7 \%$ & $16.2 \%$ & $8.1 \%$ & $100 \%$ \\
\hline YES & 08 & 10 & 08 & 26 \\
\hline TOTAL & $30.8 \%$ & $38.5 \%$ & $30.8 \%$ & $100 \%$ \\
\hline & 64 & 22 & 14 & 100 \\
\hline
\end{tabular}

Distribution of cases as per MPI in relation to ICU stay: It is inferred from the table-6 the ICU stay was quite prolonged in cases with higher MPI scores. it is quite evident that there is proportional increase in duration of stay with increase in scores. It is evident from the table that $90 \%$ of the patients who fell in MPI score $<22$ were discharged within 10 days of their hospital stay. similar findings are observed in a studies conducted by chromic etal[20] and Bosscha K etal [20]. 
Original Research Article

Table-6: MPI vs ICU stay.

\begin{tabular}{|c|c|c|c|c|}
\hline ICU STAY & SCORE $<22$ & SCORE 22-29 & SCORE $>$ 29 & TOTAL \\
\hline$<$ than 5 days & 64 & 14 & 08 & 86 \\
\hline & $74.4 \%$ & $16.3 \%$ & $9.3 \%$ & $100 \%$ \\
\hline 6 to 10 days & 00 & 08 & 02 & 10 \\
\hline & $00 \%$ & $80 \%$ & $20 \%$ & $100 \%$ \\
\hline 10 days & 00 & 00 & 04 & 04 \\
\hline & $00 \%$ & $00 \%$ & $100 \%$ & $100 \%$ \\
\hline
\end{tabular}

Distribution of cases as per MPI in relation to type of exudates and incidence of complication: It can be understood from table No.7 that presence of feculent and purulent exudates was associated with significantly increased postoperative complications requiring hospital stay. Up to $80 \%$ of the patients with clear exudates has no post-operative complications which dropped to only $30 \%(\mathrm{p}-<0.005)$. However, there was no statistically significant difference between feculent and purulent exudates, both having similar complication profiles. The findings are in concurrence with the findings projected in studies conducted by Biondo S etal[21] and Schoeffel U etal [22].

Table-7: Distribution of cases as to exudates and incidence of complications.

\begin{tabular}{|c|c|c|c|c|}
\hline Score & Clear & Purulent & Feculent & Total \\
\hline$<22$ & 52 & 10 & 02 & 64 \\
\hline & $81.25 \%$ & $15.6 \%$ & $3.125 \%$ & $100 \%$ \\
\hline $22-29$ & 06 & 12 & 04 & 22 \\
\hline & $27.27 \%$ & $54.5 \%$ & $18.18 \%$ & $100 \%$ \\
\hline$>29$ & 02 & 04 & 08 & 14 \\
\hline & $14.29 \%$ & $28.6 \%$ & $57.14 \%$ & $100 \%$ \\
\hline Total & $60(60 \%)$ & $26(26 \%)$ & $14(14 \%)$ & $100(100 \%)$ \\
\hline
\end{tabular}

\section{Conclusions}

1. There have been several attempts in the past and present for creating an effective scoring system as to predict mortality risk after emergency surgery especially in the cases of hallow viscera perforations.

2. Though few scoring systems provide an approximate prediction as to the observed mortality rate for a cohort, but none of them are sufficiently accurate to rely upon when considering an individual patient.

3. It can be concluded that this validation study of the Mannheim Peritonitis Index scoring system for predicting the morbidity and morbidity and mortality in patients with peritonitis due to hollow viscus perforation is quite beneficial. The study results indicate that MPI scoring system is a simple but forms an effective tool for assessing this group of patients and can be used as a guiding tool to decide on the management of the patient after the definitive procedure is done.

4. Among the various variables of the scoring system duration of pain, organ failure on presentation and presence of feculent exudates had a significant hand in predicting the eventual outcome of the patient.

\section{Recommendations}

The current study enabled a verification of validity and relevance with regards to applying Meinhemm Peritonitis Index to predict the outcome of surgery for Hollow viscus perforation cases at a district level hospital in emergency setting.

1. MPI can be proposed as a protocol in dealing with a common surgery performed in emergency situations.

2. MPI will enhance objective evaluation, standards of monitoring and preemptive prediction of surgical outcome.

3. MPI will enable greater transparency in healthcare facilities and hence better rapport between patient and surgeon without any gaps in the expectations about the outcome and competence of the surgeon.

4. This study gave an insight to the measurement of complications of the most common emergency surgical procedure done at a district headquarters supported by the Medical college academic supervision. 
5. MPI can be proposed to be the protocol for any district level hospital. It gives a focused attention by the surgeon for pre, intra and postoperative care and procedures.

6. It improves objective calculation of the surgery and also a presumptive medication in the progress for a patient hence provides transparency in the treatment protocol.

\section{Conflict of interest: None declared.}

\section{Funding: Nil, Permission from IRB: Yes}

Acknowledgments: The authors sincerely thank all authors and researchers; whose articles and works are used in this publication and extend unconditional apology if their opinions are mispresented.

\section{References}

1. Irvin TT. Mortality and perforated peptic ulcer: a case for risk stratification in elderly patients. Br J Surg. 1989; 76:215-18.

2. Moller MH, Engebjerg MC, Adamson S, Bendix J, Thomsen RW. The Peptic Ulcer Perforation (PULP) score: a predictor of mortality following peptic ulcer perforation. A cohort study. Acta anaesthesiologica Scandinavica. 2012;56(5):655-62.

3. Moller MH, Adamsen S, Thomsen RW, Moller AM. Preoperative prognostic factors for mortality in peptic ulcer perforation- a systematic review. Scand J Gastroenterol. 2010; 45:785-805.

4. Moller $\mathrm{MH}$, Shah $\mathrm{K}$, Bendix J, Jensen AG, Zimmermann-Nielsen E, Adamsen S, Moller AM. Risk factors in patients surgically treated for peptic ulcer perforation. Scand J Gastroenterol. 2009; 44:145-52.

5. Knaus WA, Zimmerman JE, Wagner DP, Draper EA, Lawrence DE. APACHE-acute physiology and chronic health evaluation: a physiologically based classification system. Critical Care Medicine. 1981:9.

6. [6] Boey J, Choi SKY, Alagaratnam TT, Poon A. Risk stratification in perforated duodenal ulcers. Ann Surg. 1987; 205:22-6.

7. Linder MM, Wacha H, Feldmann U, Wesch G, Streifensand RA, Gundlach E. The Mannheim peritonitis index. An instrument for the intraoperative prognosis of peritonitis. Der Chirurg; Zeitschrift fur alleGebiete der operative Medizen. 1987 Feb; 58 (2): 84-92.

\section{Original Research Article}

8. Bohen J, Boulanger M, Meakins JL, Mclean AP. Prognosis in generalized peritonitis. Relation to cause and risk factors. Arch Surg. 1983; 118:285-90.

9. Biling A, Frolich D, Schildberg F. Prediction of outcome using the Mannheim peritonitis index in 2003 patients. Br J Surg. 1994;81:209-13.

10. Smith J, Caldwell E, D'Amours S, Jalaludin B, Sugrue M. Abdominal trauma: a disease in evolution. ANZ journal of surgery. 2005 Sep 1;75(9):790-4.

11. Watts DD, Fakhry SM, EAST Multi-Institutional HVI Research Group. Incidence of hollow viscus injury in blunt trauma: an analysis from 275,557 trauma admissions from the East multi-institutional trial. Journal of Trauma and Acute Care Surgery. 2003 Feb 1; 54 (2): 289-94.

12. Ramachandra ML, Jagadesh B, Chandra SB. Clinical study and management of secondary peritonitis due to perforated hollow viscous. Archives of Medical Science. 2007 Jan 1;3(1):61-8.

13. Pacelli F, Doglietto GB, Alfieri S, Piccioni E, Sgadari A, Gui D, Crucitti F. Prognosis in intraabdominal infections: multivariate analysis on 604 patients. Archives of surgery. 1996 Jun 1; 131 (6): 641-5.

14. Lohsiriwat V, Prapasrivorakul S, Lohsiriwat D. Perforated peptic ulcer: clinical presentation, surgical outcomes, and the accuracy of the Boey scoring system in predicting postoperative morbidity and mortality. World journal of surgery. 2009 Jan 1;33(1):80-5.

15. Függer R, Rogy M, Herbst F, Schemper M, Schulz F. Validation study of the Mannheim peritonitis index. Der Chirurg; Zeitschrift fur alle Gebiete der operative Medizen. 1988 Sep;59(9):598-601.

16. Gooszen AW, Tollenaar RA, Geelkerken RH, Smeets HJ, Bemelman WA, Van Schaardenburgh P, Gooszen HG. Prospective study of primary anastomosis following sigmoid resection for suspected acute complicated diverticular disease. British journal of surgery. 2001 May 1;88(5):693-7.

17. Demmel N, Maag K, Osterholzer G. The value of clinical parameters for determining the prognosis of peritonitis--validation of the Mannheim Peritonitis Index. Langenbecks Archiv fur Chirurgie. 1994; 379 (3): 152-8. 
18. Seiler CA, Brügger L, Forssmann U, Baer HU, Büchler MW. Conservative surgical treatment of diffuse peritonitis. Surgery. 2000 Feb 1;127(2):178-84.

19. Chromik AM, Meiser A, Hölling J, Sülberg D, Daigeler A, Meurer K, Vogelsang H, Seelig MH, Uhl W. Identification of patients at risk for development of tertiary peritonitis on a surgical intensive care unit. Journal of Gastrointestinal Surgery. 2009 Jul 1;13(7): 1358-67.

20. Bosscha K, Reijnders K, Hulstaert PF, Algra A, Van der Werken C. Prognostic scoring systems to predict

\section{Original Research Article}

outcome in peritonitis and intra-abdominal sepsis. British journal of surgery. 1997 Nov 1;84(11):1532-4.

21. Biondo S, Ramos E, Fraccalvieri D, Kreisler E, Ragué JM, Jaurrieta E. Comparative study of left colonic peritonitis severity score and Mannheim peritonitis index. British journal of surgery. 2006 May 1;93(5):616-22.

22. Schoeffel U, Jacobs E, Ruf G, Mierswa F, Farthmann EH. Intraperitoneal micro-organisms and the severity of peritonitis. The European journal of surgery= Acta chirurgica. $1995 \mathrm{Jul} ; 161(7): 501-8$.

\section{How to cite this article?}

Ramaswamy Naik M, Sailaja K. A clinical study to predict the outcome of patients with hollow viscus perforation in a tertiary care hospital using manheim peritonitis index. Surgical Update: Int J surg Orthopedics. 2018;4(2):94-100. doi:10.17511/ijoso.2018.i02.07. 